\title{
Histochemical localization and assay of enzymes
}

\author{
F. W. D. ROST \\ From the Department of Histochemistry, Royal Postgraduate Medical School, London
}

Histochemistry is a combination of chemistry and histology, in which reactions are carried out on tissue sections or similar preparations and the results examined under a microscope, with the object of combining the advantages of chemical or biochemical specificity and histological localization. The armamentarium of the diagnostic pathologist has been greatly increased by the development of modern histochemical and cytochemical techniques for the demonstration of enzymes and other specific chemical substances, and for their localization in tissues, cells, and cell organelles. Histochemistry is complementary to biochemical analysis of tissue homogenates, since histochemical techniques can give simultaneously biochemical and morphological information. The histochemical approach to diagnostic pathology is therefore based on correlating the presence or absence of morphological changes with any biochemical lesions that may be present. In tissues containing more than one cell type it is invaluable to be able to carry out a reaction on the tissue and observe the results for each cell type.

\section{Applications of Enzyme Histochemistry to Diagnostic Pathology}

The present-day major applications of enzyme histochemistry to diagnostic pathology are summarized in Table I. For many of these applications (indicated by the letter L) qualitative methods are adequate, the enzyme being used as a marker or identifying characteristic of a particular tissue, cell type, or organelle to which it is more or less restricted. At the cellular level, this concept can be applied to the identification of malignant cells by the presence of a characteristic enzyme or enzyme pattern (eg, o-diphenol oxidase ${ }^{1}$ (EC 1.10.3.1) in malignant melanoma). At the subcellular level, methods for specific enzymes can be used for the investigation of lesions involving organelles containing the enzymes.

Applications of enzyme histochemistry to diagnostic pathology have recently been reviewed by Sobel (1968). Histochemistry is already of major importance in the diagnosis of disorders of skeletal 'DOPA oxidase'.
Differential diagnosis of tumours (L)

o-Diphenol oxidase ${ }^{1}$ (EC 1.10.3.1) in melanoma

Acid phosphatase (EC 3.1.3.2) in prostatic carcinoma* and osteoclastoma

Alkaline phosphatase (EC 3.1.3.1) in adenocarcinoma of the lung*, seminoma of the testis*, and bone-forming tumours (osteosarcoma) Leucine aminopeptidase (EC 3.4.1.1) in tumours of the stomach* bile ducts*, kidney*, mammary gland*, and fibrosarcoma*. Its presence in lymph node metastases strongly suggests carcinoma of stomach or bile duct*

ATPase (EC 3.6.1.3) in reticulum cell sarcoma (versus anaplastic carcinoma*)

Glycerolphosphate dehydrogenase (EC 1.1.99.5) in endocrine polypeptide (APUD) tumours

Characterization of tumours for prognosis $(Q)$

Level of carboxylesterase (EC 3.1.1.1) ${ }^{2}$ in squamous carcinoma of lung; the lower the esterase activity, the worse the prognosis*

Level of alkaline phosphatase gives some indication of the prognosis of fibrosarcoma*

Characterization of non-neoplastic lesions $(L, Q)$

ATPase, glycogen phosphorylase (EC 2.4.1.1) reduced NAD dehydrogenase $^{3}$ (EC 1.6.99.3) and acid phosphat ase in various skeletal muscle diseases

Jejunal acid phosphatase in coeliac disease (Wall et al, 1970)

Reduced NAD dehydrogenase and carboxylesterase (Garret and Howard, 1969) for demonstrating neurones in Hirschsprung's disease Glycogen phosphorylases and glucose 6-phosphatase (EC 3.1.3.9) in glycogen storage diseases; also acid phosphatase in Pompe's disease (Lake, 1970)

Table I Application of enzyme histochemistry to diagnostic pathology

$\mathbf{L}=$ localization is significant, $\mathbf{Q}=$ quantity is significant.

* = Data obtained from a personal communication (1969) from Dr R. G. J. Willighagen, Pathologisch Laboratorium der Rijksuniversiteit, Leiden, The Netherlands,

'Dopa oxidase'

'Nonspecific esterase'

'NADH diaphorase'

muscle (Dubowitz and Pearse, 1964; Engel, 1965; Pearse and Johnson, 1970; Bethlem, 1970). Other reviews include those on enzyme histochemistry in relation to neoplasms (Burstone, 1962), neuropathology (Adams, 1965), bone tumours (Jeffree and Price, 1965), cardiovascular pathology (Adams, 1967), and glycogen storage diseases (Lake, 1970). Other recent papers of practical importance deal with Hirschsprung's disease (Garrett and Howard, 1969) and coeliac disease (Wall, Douglas, Booth, and Pearse, 1970). 


\section{Material}

Enzyme histochemistry can be carried out on tissue sections or on smears. The histochemist's requirements for tissue section preparation are much more stringent than those of the conventional morbid anatomist, whose sole requirement is what he calls a good paraffin section-incorporating a standard set of morphological artefacts and of almost no biochemical value. The histochemist requires that his tissue sections should approach as closely as possible to thin slices of the original tissue, consistent with the preservation of both the structure of the tissue and the biochemical identity and activity of its constituents. Unfortunately attempts to combine histological and biochemical methods on the same preparation lead to conflict between the technical requirements for preservation of both the biochemical activity of enzymes and of the morphological integrity of the tissue. This inevitably leads to compromise.

Biopsy and other material intended for histochemical examination must of course be fresh; once removed from the body, it must be preserved without delay by freezing or fixation. Subsequent processing of the tissue is made more complicated by the necessity not only to maintain the morphological integrity of the tissue, but also to preserve and prevent diffusion of substances of interest, eg, enzymes, from their proper sites.

Morphological stabilization or 'fixation' is carried out by chemical treatment, usually directed mainly towards cross-linkage of proteins and rendering proteins insoluble by denaturation. Typical substances used for fixation are aldehydes or ketones (formaldehyde, glutaraldehyde, acetone) and alcohols (methanol, ethanol). The effects of fixatives on enzyme localization have been reviewed by Burstone (1958) and Pearse (1968, chapter 14). Unfortunately the process of fixation, necessary to preserve localization and to prevent diffusion of soluble enzymes into the incubation mixture, itself causes loss of enzyme activity mainly by denaturation of enzyme protein. Fixation must therefore be accepted as a necessary evil, the deleterious effects of which must be minimized by careful choice of fixative, chosen according to the particular enzyme to be studied. In this context the most widely used fixatives are buffered formaldehyde solutions and acetone, both at a low temperature (Seligman et al, 1951; Gomori, 1952).

Preparation of tissue sections usually involves freezing to a solid block, after which sections are cut either on a cryostat or after freeze-drying and embedding in a low-melting-point wax. Fixation may be carried out either before freezing or after cutting sections. Freeze-dried material can be fixed $\stackrel{\rho}{\bar{P}}$ by gaseous fixatives before embedding. For detailso of these techniques see Pearse (1968), Bancrof $\vec{E}$ (1967), and Eckner, Riebe, Moulder, and Blackstone (1968).

\section{Histochemical Methods for Enzyme Localization}

Only about 100 enzymes can be demonstrated histochemically because of the difficulties inheren in preserving histological localization of the enzymes and of its reaction products. The majority ares either hydrolytic or oxidative. A list of the most important is given by Pearse (1968, chapter 14) and for details of individual methods, see Pearse (1968 and 1971) and Bancroft (1967).

In designing methods for the histochemicaf demonstration of enzymes, the aim is in all casest to obtain a reaction product which is localized at the site of enzyme activity and is either visible or easily rendered so. The final reaction product (FRP) should therefore be insoluble except in certain kinetic studies, to be described below In principle the FRP can be visualized by any of the following properties: (1) opacity to visible light, ultraviolet light, or an electron beam (elec $\overrightarrow{6}$ tron microscopy); (2) luminescence-either fluorosscence or phosphorescence; (3) retardation (in:crease in local refractive index); and (4) reflectivity.

The majority of current methods lead to a coloures or black final reaction product. Electron opacity is of course a sine qua non for electron microscopic in vestigations. The use of ultraviolet absorption has been suggested by Young and Edwards (1963) for th $\vec{E}$ visualization of formazan deposits produced in methods for oxidative enzymes. Fluorescence methods్ have not yet been properly explored, but offer grea? hope for the future because of the high sensitivity which can be achieved by fluorescence techniques: Phosphorescence has not, so far as I am aware, beew. applied in this context, nor is it likely to be relevanto. Retardation methods (eg, interferometry) may havę something to offer, and might be of value in the study of living intact cells, for which fluorescence techniques are otherwise likely to prove of greates? value.

The basic principles of current methods for the demonstration of enzymes will be illustrated bjo reference to the most important procedures fo: hydrolytic enzymes and dehydrogenases. Althougk methods for a few enzymes have been known fok a long time, modern enzyme histochemistry daté from the method for alkaline phosphatase (E\& 3.1.3.1) developed independently by Gomori (1939) and by Takamatsu (1939). In this method, phosphato released from the substrate by the enzyme is precid 
pitated as calcium phosphate, which in turn is made visible by the reaction of von Kóssa or by some other method. By choice of appropriate substrate and with various minor modifications, this method has been adapted to the demonstration of a variety of specific and nonspecific phosphatases, using both optical and electron microscopy. Of even greater importance was the basic principle of the method, ie, the use of a 'capture reagent' to precipitate one of the enzymatic products at the site of enzymatic activity. This principle is the basis of the majority of methods for hydrolytic enzymes in common use today. In the current modification of the Gomori method for alkaline phosphatase (Pearse, 1968) the phosphate is captured by calcium ions and precipitated as calcium phosphate Fig. 1). The precipitate is converted successively to cobalt phosphate and to cobalt sulphide, which is opaque. In a similar method for acid phosphatase (EC 3.1.3.2), lead is used as the capture reagent and the precipitate of lead phosphate is converted directly to lead sulphide.

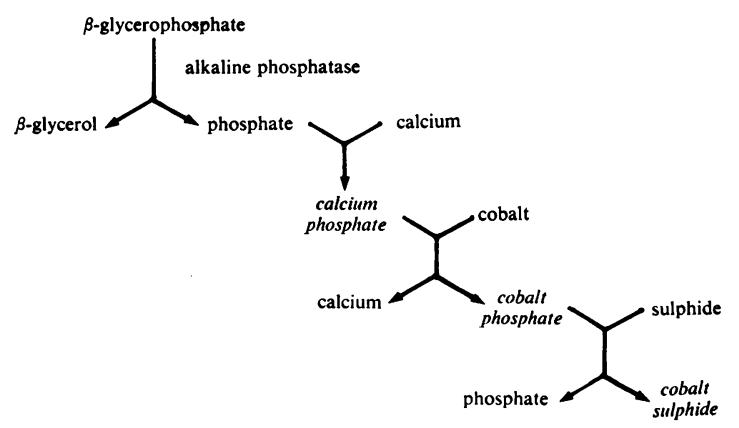

Fig. 1 Use of calcium ions to capture phosphate liberated by alkaline phosphatase, with conversion to opaque cobalt sulphide.

As an alternative to capture of the released phosphate, an artificial substrate may be used where the released alkyl moiety can be coupled to an azo dye (Menten, Junge, and Green, 1944). By the use of this principle, other salts and esters can be used as substrates to demonstrate sulphatases (EC 3.1.6), esterases (EC 3.1.1), and lipases (EC 3.1.1.3).

Methods for the demonstration of hydrolytic enzymes have been largely based on principles laid down by Nachlas, Young, and Seligman (1957b). Since then, additional possibilities have been opened up by the development of fluorescence techniques. The present possibilities are summarized in Table II.

The simultaneous capture method has already been exemplified by the Gomori methods for
Capture (coupling, conversion, chelation)

Simultaneous

Post-incubation

Solubility change

Coloured or chromogenic substrate

Fluorescent or fluorogenic substrate

Diffusible product (for kinetic studies)

Fluorogenic substrate

Table II Histochemical reactions for hydrolytic enzymes

phosphatases, whereby a soluble product of the enzymatic reaction, the primary reaction product (PRP), phosphate, is precipitated by reacting with a capture reagent, calcium or lead, present in the incubation mixture. In the coupling methods the capture reagent is a diazonium salt. The coupling reaction may be carried out after incubation; this may be advantageous in cases where the presence of a capture reagent in the incubation medium might lead to enzyme inhibition, but disadvantageous in that the PRP is more liable to diffusion before coupling and precipitation can take place, with corresponding inaccuracy in localization.

Methods involving the principle of altered solubility are based on the employment of soluble substrates which give rise to an insoluble product. The insoluble product is then presumed to precipitate at the site of enzyme activity. The visualization of the precipitate may depend upon the use of a coloured substrate, or of a substrate which after hydrolysis undergoes molecular rearrangement to give a highly coloured or fluorescent product. Methods making use of the principle of altered solubility of a coloured substrate have been described for alkaline phosphatase (Loveless and Danielli, 1949) and $\beta$-glucuronidase (EC 3.2.1.31) (Friedenwald and Becker, 1948). The potential development of methods of this type appears to be limited by the small number of known enzymesensitive solubilizing groups.

In fluorogenic methods, the substrate should be soluble and preferably non-fluorescent, and the reaction product insoluble and fluorescent. Some naphthol derivatives appear suitable (Burstone, 1962; F. W. D. Rost, unpublished data). Further development of fluorogenic methods is likely to be valuable, because of the high sensitivity with which fluorescent reaction products can be detected, as well as the increased range of possible substances to be used and the possibilities of microfluorimetry for quantitation.

Methods utilizing fluorescent but diffusible primary reaction products are not normally applicable to investigation of localization, but may be of 


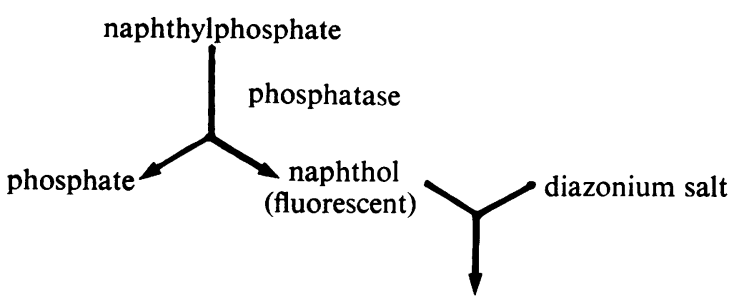

precipitate

(coloured)

Fig. 2 The use of naphthylphosphate for the histochemical study of alkaline phosphatase. The reaction may be followed by measuring the fluorescence developed or the precipitate formed.

great value in kinetic studies. Fluorescein esters have been used for this purpose in the investigation of properties of cell membranes (Rotman and Papermaster, 1966; Sernetz, 1969). These esters are water-soluble and non-fluorescent and, being non-polar, they can traverse intact cell membranes to sites where free fluorescein is released by the action of esterases. Fluorescein itself, being polar, cannot easily pass the cell membrane and therefore accumulates in the cell where it is visualized by its fluorescence. Naphthyl phosphates have been used for microfluorimetric studies of the kinetics of alkaline phosphatase (Rost, Nägel, and Moss, 1970) as shown in Figure 2.

In principle, methods for dehydrogenases are based on allowing the enzyme to act on its natural substrate in the presence of any necessary coenzymes and of a tetrazolium salt. This latter, itself almost colourless and water-soluble, becomes reduced to a formazan which precipitates as an insoluble coloured crystalline deposit. The deposits can be visualized by their absorption of red, violet, and ultraviolet light, and by their highly refractile crystalline structure. Important criteria for selection of a tetrazolium salt are its redox potential, the size, shape, and solubility of the crystalline formazan deposit produced, and the degree of enzyme inhibition due to its presence. The salts most commonly used are ditetrazolium chloridenitro-BT (NBT) introduced by Nachlas, Tsou, Souza, Cheng, and Seligman (1957a) and 3(3:5-dimethylthiazolyl-2)2:5-diphenyltetrazolium bromide (MTT) introduced by Pearse (1957). In the case of the latter (MTT), cobalt is included in the incubation medium to be immediately chelated by the formazan, producing a deeply coloured and finely granular deposit.

CRITERIA FOR CHOICE OF SUBSTRATE

In methods for hydrolytic enzymes it is not generally necessary or desirable to use the natural substrate of the enzyme, an artificial substrate (eg, a naphthy derivative) being usually more suitable. The essentialo properties required of the substrate are: (1) specificity for the relevant enzyme or enzymes; (2) waterv solubility; (3) low molecular weight; and (4) non=o polarity.

The last three characteristics are necessary to $\overline{\bar{n}}$. permit the substrate to diffuse sufficiently rapidlyळ into the tissues and reach the sites of enzyme activityo in sufficient concentration for the reaction to haves zero order kinetics, otherwise the amount of finalo reaction product will not be proportional to the $\overrightarrow{-}$ amount of enzyme activity (van Duijn, Pascoe,,$\omega$ and Ploeg, 1967; Pearse, 1968, chapter 14). Polaro groups on the substrate molecule may lead to binding to tissue components and interference with $\overrightarrow{\vec{s}}$ diffusion, and will hinder or prevent diffusion through lipoprotein membranes; this is particularly important when dealing with intact cells or enzyme systems enclosed in lipid or lipoprotein membranes. A high degree of diffusibility will also facilitatec removal of unused substrate after completion of the reaction.

It is desirable that both the primary and finak reaction products should be insoluble not only in $\overrightarrow{0}$ water but also in lipids, since otherwise they may tend to be concentrated in the latter. Strong polar ${ }^{3} y_{\square}$ should normally be avoided, since this may lead ${ }^{\circ} 00$ binding of the PRP to acidic or basic proteins rathers than to the capture reagent, but may be of value too prevent the reaction products from diffusing through membranes.

The primary difficulty in assessing the accuracyo흘 of histochemical localization of an enzyme is the absence in many cases of any alternative method against which the accuracy of histochemical tech niques can be judged. Only in a few cases, where the enzyme is predominantly mitochondrial or micro $-\overline{0}$ somal, is biochemical evidence sufficiently strong to provide adequate criteria. It is possible that in the future the greater resolution of electron microscopy and the greater sensitivity of fluorescenceo methods may shed further light on this problem? At present, the enzyme histochemist usually judgeso accuracy of localization on the basis of the apparene. sharpness of localization, assuming that if ones method gives an apparently sharply defined locali $\sim$ zation whereas a second gives a diffuse one, the latter is likely to be less accurate. That this principle $e_{-}^{\omega}$ is not always valid is evident from the demon stration by several workers that partial inactivatione of an enzyme by the coupling reagent will lead tos apparently better localization (Nachlas et al, $1957 \mathrm{~b}$ Pearse, 1968, chapter 14).

In summary, the accuracy of apparent localia 
zation of an enzyme within the cell is determined jointly by properties of the enzyme and of the chemical reaction used to demonstrate its presence. It depends on the degree of diffusion of the enzyme, of the primary reaction product, and of the final reaction product. The best localization is achieved by careful selection of the conditions for the reaction (Nachlas et al, 1957b) and for the protection of the tissue and its organelles (Scarpelli and Pearse, 1958).

\section{Histochemical Assay of Enzymes}

The goal of quantitative histochemistry has been stated to be 'the quantitative chemical analysis of the cell, its parts and its extracellular products, in situ and in the living state' (Glick, 1953). It must be admitted that for enzymes, and indeed for most substances, this goal is far from being realized. Methods for biochemical assay of enzymes have become routine; histochemical localization is perhaps not so far behind, but the combination of the two still presents great difficulties except in special favourable circumstances. It seems that accuracies of localization and quantitation have a kind of reciprocal relationship whereby any increase in one, beyond a certain limit, requires a corresponding decrease in the other.

One approach to quantitative histochemistry involves the isolation of the regions of interest by microdissection, differential centrifugation, or other means followed by conventional microanalysis. Methods of this type are capable of accurate quantitation but only imprecise localization (for a review of methods of this type see Glick, 1963). The other approach involves quantitation in the intact cell. Current methods of this type have been reviewed in a series of papers edited by Wied (1966); in principle, the specimen is examined under a microscope, the region of interest is defined and isolated by an optical diaphragm, and measurements are made of the light absorption, fluorescence, reflectivity, or retardation due to the final reaction product. Similar measurements are made on a standard and the results compared.

Absorption methods have so far attracted the most attention (for a more detailed review see Mendelsohn, 1966). The major difficulty of absorptiometry (densitometry) is distribution error (Ornstein, 1952), because absorption measurements can be made accurately only if the optical density of the specimen is uniform within the measuring field. It is therefore necessary to break up the region to be measured into a large number of smaller fields within each of which the optical density is uniformly distributed, and to integrate the results from each of these measurements.

Instrumentation for quantitative cytochemistry by absorptiometry was pioneered by Caspersson and his coworkers (Caspersson, Jacobsson, Lomakka, Svensson, and Säfström, 1953; Caspersson, 1954, 1955). Apparatus for scanning microdensitometry, the Vickers M85, is commercially available in this country. A computer-controlled scanning system, the Zeiss (Oberkochen) scanning microphotometer, offers particular advantages in the choice of area to be measured.

Alternatives to scanning microdensitometry are the two-wavelength method (Ornstein, 1952; Patau, 1952) and photographic methods (den Tonkelaar and van Duijn, 1964).

Fluorimetry does not suffer from distributional error, the fluorescence from different parts of the measuring field being additive. As in absorptiometry, two measurements are needed, the intensities of the incident light and of the fluorescence. Direct measurement of the incident light is not technically possible with present-day microfluorimeters, even with those incorporating a reference channel. Instead, the fluorescence is compared with that of a standard. The development of microfluorimetry has long been hindered by lack of suitable standards, but this problem appears to have been solved by the development of fluorescence standards consisting of standard solutions held in capillary tubes (Sernetz and Thaer, 1970). The most obvious advantages of microfluorimetry are (1) freedom from distributional error and (2) high sensitivity. Freedom from distributional error means that scanning is not necessary; this simplifies the equipment necessary and greatly reduces the length of time required for each determination, since only one reading is required instead of many. A disadvantage of microfluorimetry is non-linearity at high concentrations of fluorophore (Udenfriend, 1962; Rigler, 1966). In practice this should present no difficulty.

Instrumental requirements for microfluorimetry have been reviewed by Thaer (1966). There are several commercially available instruments employing filters, but at present the only commercially available microspectrofluorimeter appears to be that of Leitz (Björklund, Ehinger, and Falck, 1968; Pearse and Rost, 1969) which has monochromators for both excitation and emission.

The other major difficulty in quantitative histochemistry lies in defining the region of the specimen to be measured. The problem is easiest in the special case of isolated or isolatable cells, such as leucocytes in a smear of blood or bone marrow, or tissue culture cells, on which the most successful quantitative histochemistry to date has been carried out, 
eg. determination of alkaline phosphatase in leucocytes (van der Ploeg and van Duijn, 1968). Subject to the difficulties which have been outlined above concerning loss of enzyme and primary reaction products, it should be fairly easy to carry out quantitative estimations of enzymes in cell smears, using either absorptiometry or fluorimetry, and it is to be hoped that applications to clinical haematology and possibly exfoliative cytology will soon become routine.

Tissue sections are another matter. There are two difficulties, namely, variations in thickness of the section, and the problem of isolating an irregularly shaped cell contiguous from its neighbours. The thickness of a section cannot be assumed, even approximately, to equal the number of microns to which the microtome is set, nor can serial sections be absolutely guaranteed to be of identical thickness. For example, every microtomist is familiar with the phenomenon of alternate thick and thin sections, which is obvious when blatant, but which is easily missed when slight. Finally, the isolation in a measuring diaphragm of an image of a single cell of irregular shape is like fitting a square peg into a round hole. One approach to this problem is that of the new Zeiss scanning photometer, the computer of which can be instructed to integrate measurements within an irregular area; the conversation which is required between computer and operator is at present lengthy, but in the future a light-pen could be used to define the measuring area.

Comparative or statistical studies of a cell population within a single preparation avoid some of the difficulties of quantitative assay. Skeletal muscle cells, reasonably homogenous in transverse section, can be compared within a single section either by measuring from a standard-sized area small enough to fit into each cell or by a computerized scanning technique. We have applied the former method to the study of the distribution of glycogen phosphorylase (M. Johnson and F. W. D. Rost, unpublished data). Alternatively an instrument such as the MRC television image analyser may be used whereby it is possible to measure the relative areas in a section occupied by muscle fibres of types I and II (and III, if present) using ATPase (EC 3.6.1.3) or reduced NAD dehydrogenase (EC 1.6.99.3) as a marker (F. W. D. Rost, unpublished data). In principle phosphorylase could be used, but in our hands this has so far proved less satisfactory because of irregularities in staining.

ACCURACY OF ENZYME ASSAYS

Enzyme assay by histochemical methods involves three stages: demonstration of the enzyme; measure- ment of the optical density or fluorescence intensity of the final reaction product; and the process of ${ }^{D}$ relating the numerical result obtained to the actual amount of enzyme activity present per topographic - unit (ie, activity per cell, unit weight, or organelle). $\overrightarrow{\overrightarrow{2}}$

Loss of enzyme activity can occur in several ways, of which the most important are believed to be actual loss of the enzyme by diffusion, and inactiva- $\frac{\overline{\bar{n}}}{\overline{5}}$. tion of the enzyme by the fixative, by subsequent $\frac{\bar{\Phi}}{\mathrm{Q}}$ tissue processing, or by substances present in the incubation mixture.

The amount of loss by diffusion varies for each $\overrightarrow{0}$ enzyme, and for each fixative. One function of the fixative is of course to prevent diffusion of the en- $\vec{\omega}$ zyme into the incubation mixture, but unfortunately some diffusion invariably takes place into the? fixative itself, and moreover the process of fixation results in some inactivation of the enzyme. In practice, a compromise may have to be reached between $\overrightarrow{\vec{A}}$ adequate fixation for accurate localization, and $\mathrm{a}^{\mathrm{\omega}}$ lesser degree of fixation with preservation of enzyme activity. Fixation notwithstanding, some diffusionof enzyme will take place into the incubation medium, the extent of this loss being influenced by the duration of incubation, temperature, $p \mathrm{H}$, the electrolyte concentration, and substances which may be $\frac{1}{0}$ added to the incubation medium specially to reduges enzyme diffusion.

Measurements on tissue sections, unless used foro comparison with a single section, are dependents upon knowledge of the section thickness. There does not appear to be any really satisfactory methodő at present for measuring section thickness; inter- $\varrho$ ferometry offers the best hope.

Finally there is the question of instrumental 3 error in measurement of optical density or fluorescence. This is a purely technical problem, and is? probably the least significant source of error in this context.

Obviously the final evaluation of any quantitative $\frac{\bar{\sigma}}{3}$ histochemical system will depend upon comparison. with results obtained by such other procedures $ᄋ$ as may be available, and upon the results of calibration by proper model systems. Model systems오 based on the incorporation of alkaline or acid $\$$ phosphatase into polyacrylamide gels have been thoroughly investigated by van Duijn and his N coworkers (van Duijn et al, 1967; Lojda, van der Ploeg, and van Duijn, 1967; van der Ploeg and van Duijn, 1968).

\section{Kinetic Studies}

Kinetic studies of oxidative enzyme systems in? living cells have been made by microfluorimetry, $\frac{T}{O}$ utilizing the fluorescence of reduced pyridine $\stackrel{\mathbb{D}}{\stackrel{P}{*}}$ 
nucleotide (Chance and Thorell, 1959; Chance, 1962; Kohen and Kohen, 1966).

Rotman and Papermaster (1966) observed that living cells in a medium containing certain fluorescein esters of fatty acids became fluorescent. This was due to the nonpolar ester passing through the cell membrane and becoming hydrolyzed by intracellular esterases to produce free fluorescein which, being polar, could not readily pass the cell membrane and therefore accumulated in the cell. This phenomenon allows kinetic investigations of the properties of cell membranes (Rotman and Papermaster, 1966; Sernetz, 1969).

The use of cryostat sections of isolated living cells for enzyme kinetic studies has several potential advantages compared with the use of enzyme solutions. For example, alkaline phosphatase can only be obtained free in solution by vigorous procedures such as autolysis or extraction with n-butanol, since it is firmly bound to structural elements of the cells in which it occurs. These extraction procedures are potentially disruptive of enzyme structure and therefore it may be doubted whether characteristics of the enzyme solution such as substrate specificity, Michaelis constant, $p \mathrm{H}$ optimum, or response to activators or inhibitors truly reflect the properties of the enzyme within the living cell. Jeffree (1970) investigated the effects of $p \mathrm{H}$ and inhibitors upon the phosphatases of osteoclasts using a semiquantitative azo-dye technique. Täljedal (1970) studied the apparent $\mathbf{K}_{m}$ of glucose 6-phosphatase in cryostat sections by microfluorimetry of reduced pyridine nucleotide. Rost et al (1970) reported preliminary experiments using $\alpha$-naphthyl orthophosphate as a fluorogenic substrate for alkaline phosphatase (Moss, 1960), which was studied in cryostat sections mounted in the flow chamber of the MRC microspectrofluorimeter (Pearse and Rost, 1969); they obtained an apparent $\mathrm{K}_{m}$ value of $1.1 \mathrm{mM}$ at $p \mathrm{H} 10 \cdot 1$, which is in good agreement with the value of $0.8 \mathrm{mM}$ at the same $p \mathrm{H}$ for the soluble enzyme. The $p \mathrm{H}$-dependence of the activity of the enzyme in tissue sections was also similar to that of the enzyme in solution.

\section{Conclusions}

The correlation of structure and biochemical function made possible by histochemical techniques is of unique value in diagnostic and experimental pathology. Quantitative histochemical methodology for enzymes is still in its infancy, but offers great potential for the assay and characterization of enzymes in situ, particularly in single living cells. Histochemical methods for the demonstration of enzymes are at present of greatest value in the diagnosis of neoplasms and of skeletal muscle disorders, but can be applied in principle to the whole range of pathological conditions.

\section{References}

Adams, C. W. M. (Ed.) (1965). Neurohistochemistry, Elsevier, Amsterdam.

Adams, C. W. M. (1967). Vascular Histochemistry in Relation to the Chemical and Structural Pathology of Cardiovascular Disease. Lloyd-Luke, London.

Bancroft, J. D. (1967). An Introduction to Histochemical Technique. Butterworths, London.

Bethlem, J. (1970). Muscle Pathology. Introduction and Atlas. NorthHolland Publishing Co., Amsterdam.

Björklund, A., Ehinger, B., and Falck, B. (1968). A method of differentiating dopamine from noradrenaline in tissue sections by microspectrofluorometry. J. Histochem. Cytochem., 16, 263-270.

Burstone, M. S. (1958). The relationship between fixation and techniques for the histochemical localization of hydrolytic enzymes. J. Histochem. Cytochem. 6, 322-339.

Burstone, M. S. (1962). Enzyme Histochemistry and its Application to the Study of Neoplasms. Academic Press, New York.

Caspersson, T. (1954). A set of instrumentation for general quantitative cytochemical work by high resolution microspectrography. Exp. Cell Res., 7, 598-600.

Caspersson, T. (1955). Quantitative cytochemical methods for the study of cell metabolism. Experientia (Basel), 11, 45-88.

Caspersson, T., Jacobsson, F., Lomakka, G., Svensson, G., and Säfström, R. (1953). A high resolution ultra microspectrophotometer for large scale biological work. Exp. Cell Res., $5,560-563$.

Chance, B. (1962). Kinetics of enzyme reactions within single cells. Ann. N.Y. Acad. Sci., 97, 431-448.

Chance, B., and Thorell, B. (1959). Localization and kinetics of reduced pyridine nucleotide in living cells by microfluorometry. J. biol. Chem., 234, 3044-3050.

Dubowitz, V., and Pearse, A. G. E. (1964). Histochemical aspects of muscle disease. In Disorders of Voluntary Muscle, edited by J. N. Walton, Ch. 8, pp. 194-219. Churchill, London.

Duijn, P. van, Pascoe, E., and Ploeg, M. van der (1967). Theoretica and experimental aspects of enzyme determination in a cytochemical model system of polyacrylamide films containing alkaline phosphatase. J. Histochem. Cytochem., 15, 631-645.

Eckner, F. A. O., Riebe, B. H., Moulder, P. V., and Blackstone, E. H. (1968). Histochemical study of enzyme systems in frozen dried tissue. Histochemie, 13, 283-288.

Engel, W. K. (1965). Diseases of the neuromuscular junction and muscle. In: Neurohistochemistry, edited by C. W. M. Adams, Ch. 17, pp. 622-672. Elsevier, Amsterdam.

Friedenwald, J. S., and Becker, B. (1948). The histochemical localization of glucuronidase. J. cell. comp. Physiol., 31, 303-309.

Garrett, J. R., and Howard, E. R (1969). Histochemistry and the pathology of Hirschsprung's disease. Proc. roy. micr. Soc., 4, 76-78.

Glick, D. (1953). A critical survey of current approaches in quantitative histo- and cytochemistry. Int. Rev. Cytol., 2, 447-474.

Glick, D. (1963). Quantitative Chemical Techniques of Histo- and Cytochemistry. Interscience, New York.

Gomori, G. (1939). Microtechnical demonstration of phosphatase in tissue sections. Proc. Soc. exp. Biol. (N.Y.), 42, 23-26.

Gomori, G. (1952). Microscopical Histochemistry: Principles and Practice. University of Chicago Press, Chicago.

Jeffree, G. M. (1970). The histochemical differentiation of various phosphatases in a population of osteoclasts by a simultaneous coupling method using different diazonium salts, with observations on the presence of inhibitors in stable diazonium salts. Histochem. J., 2, 231-242.

Jeffree, G. M., and Price, C. H. G. (1965). Bone tumours and their enzymes. J. Bone Jt Surg., 47B, 120-136.

Kohen, E., and Kohen, C. (1966). A study of glycolytic control mechanisms in giant tissue culture ascites cells by microfluorimetry-microelectrophoresis. Histochemie, 7, 348-356.

Lake, B. D. (1970). The histochemical evaluation of the glycogen storage diseases. A review of techniques and their limitations. Histochem. J., 2, 441-450. 
Lojda, Z., Ploeg, M. van der, and Duijn, P. van (1967). Phosphates of the naphthol AS series in the quantitative determination of alkaline and acid phosphatase activities "in situ" studied in polyacrylamide membrane model systems and by cytospectrophotometry. Histochemie, 11, 13-32.

Loveless, A., and Danielli, J. F. (1949). A dye phosphate for the histo- and cyto-chemical demonstration of alkaline phosphatase, with some observations on the differential behaviour of nuclear and extranuclear enzymes. Quart. J. micr. Sci., 90, 57-66.

Mendelsohn, M. L. (1966). Absorption cytophotometry: comparative methodology for heterogenous objects, and the two-wavelength method. In Introduction to Quantitative Cytochemistry, edited by G. L. Wied, pp. 202-215. Academic Press, New York.

Menten, M. L., Junge, J., and Green, M. H. (1944). A coupling histochemical azo-dye test for alkaline phosphatase in the kidney. J. biol. Chem., 153, 471 .

Moss, D. W. (1960). Kinetics of phosphatase action on naphthyl phosphates, determined by a highly sensitive spectrofluorimetric technique. Biochem. J., 76, 32P.

Nachlas, M. M., Tsou, K. C., Souza, E. de, Cheng, C.S., and Seligman, A. M. (1957a). Cytochemical demonstration of succinic dehydrogenase by the use of a new p-nitrophenyl substituted ditetrazole. J. Histochem. Cytochem., 5, 420-436.

Nachlas, M. M., Young, A. C., and Seligman, A. M. (1957b). Problems of enzymatic localization by chemical reactions applied to tissue sections. J. Histochem. Cytochem., 5, 564-583.

Ornstein, L. (1952). The distributional error in microspectrophotometry. Lab. Invest., 1, 250-265.

Patau, K. (1952). Absorption microphotometry of irregular shaped objects. Chromosoma (Berl.), 5, 341-362.

Pearse, A. G. E. (1957). Intracellular localization of dehydrogenase systems using monotetrazolium salts and metal chelation of their formazans. J. Histochem. Cytochem., 5, 515-527.

Pearse, A. G. E. (1968). Histochemistry, Theoretical and Applied, 3rd ed., vol. 1. Churchill, London.

Pearse, A. G. E. (1971). Histochemistry, Theoretical and Applied, 3rd ed vol. 2, in press, Churchill, London.

Pearse, A. G. E., and Johnson, M. (1970). Histochemistry in the study of normal and diseased muscle, with special reference to myopathy with tubular aggregates. In Muscle Diseases (Excerpt a Medica International Congress Series No. 199), Excerpta Medica, Amsterdam, pp. 25-32.

Pearse, A. G. E., and Rost, F. W. D. (1969). A microspectrofluorimeter with epi-illumination and photon counting. J. Microscopy, 89, 321-328.

Ploeg, M. van der, and Duijn, P. van (1968). Cytophotometric deter- mination of alkaline phosphatase activity of individual neutrophilic leukocytes with a biochemically calibrated model system. T J. Histochem. Cytochem., 16, 693-706.

Rigler, R., Jr. (1966). Microfluorometric characterisation of intracellular nucleic acids and nucleoproteins by Acridine Orange. Acta physiol. scand., Suppl. 267.

Rost, F. W. D., Nägel, L. C. A., and Moss, D. W. (1970). Microच fluorimetric investigation of enzyme kinetics in fixed and unfixed tissue sections. Proc. roy. micr. Soc., 5, 76-77.

Rotman, B., and Papermaster, B. W. (1966). Membrane propertieso of living mammalian cells as studied by enzymatic hydrolysis of fluorogenic esters. Proc. nat. Acad. Sci. (Wash.), 55, 134-141

Scarpelli, D. G., and Pearse, A. G. E. (1958). Physical and chemica protection of cell constituents and the precise localization of enzymes. J. Histochem. Cytochem., 6, 369-376.

Seligman, A, M., Chauncey, H. H., and Nachlas, M. M. (1951) Effect of formalin fixation on the activity of five enzymes of rat liver. Stain Techn., 26, 19-23.

Sernet z, M. (1969). Personal communication.

Sernetz, M., and Thaer, A. (1970). A capillary fluorescence standardo for microfluorometry. J. Microscopy, 91, 43-52.

Sobel, H. J. (1968). Enzyme cytochemistry for the pathologist-O a simple method for the ultrastructural study of tissue alterais tions with the light microscope. Path. Ann., 3, 57-104.

Takamatsu, H. (1939). Histologische und biochemische Studien über $A$ die Phosphatase; histochemische Untersuchungsmethodikder Phosphatase und deren Verteilung in verschiedenen $A$ Organen und Geweben. Trans. Jap. path. Soc., 29, 492-498.

Täljedal, I. B. (1970). Direct fluorophotometric recording of enzyme음 kinetics in cryost at sections. Histochemie, 21, 307-313.

Thaer, A. (1966). Instrumentation for Microfluorometry. In Introduction to Quantitative Cytochemistry, edited by G. L. Wied pp. 409-426. Academic Press, New York.

Tonkelaar, E. M. den, and Duijn, P. van (1964). Photographic colorimetry as a quantitative cytochemical method. I. Prin ciples and practice of the method. Histocherrie, 4, 1-9.

Udenfriend, S. (1962). Fluorescence Assay in Biology and Medicine $\vec{c}$ Academic Press, New York.

Wall, A. J., Douglas, A. P., Booth, C. C., and Pearse, A. G. E. (19尺) The response of the jejunal mucosa in adult coeliac disease oral prednisolone. Gut, 77, 7-14.

Wied, G. L. (Ed.) (1966). Introduction to Quantitative Cytochemis Academic Press, New York.

Willighagen, R. G. J. (1969). Personal communication.

Young, M. R., and Edwards, R. G. (1963). Ultraviolet microscop صి and the detection of formazan deposits. J. Histochem. Cytochem. $11,444-446$. 